This item was submitted to Loughborough's Research Repository by the author.

Items in Figshare are protected by copyright, with all rights reserved, unless otherwise indicated.

\title{
Appetite for or resistance to consumption relationships? A trans-European perspective on the marketization of football fan relationships
}

PLEASE CITE THE PUBLISHED VERSION

https://doi.org/10.1177/1469540517747092

\section{PUBLISHER}

SAGE Publications @ The Authors

VERSION

AM (Accepted Manuscript)

\section{PUBLISHER STATEMENT}

This work is made available according to the conditions of the Creative Commons Attribution-NonCommercialNoDerivatives 4.0 International (CC BY-NC-ND 4.0) licence. Full details of this licence are available at: https://creativecommons.org/licenses/by-nc-nd/4.0/

\section{LICENCE}

CC BY-NC-ND 4.0

\section{REPOSITORY RECORD}

Bodet, Guillaume S.P., James Andrew Kenyon, and Alain Ferrand. 2019. "Appetite for or Resistance to Consumption Relationships? A Trans-european Perspective on the Marketization of Football Fan Relationships". figshare. https://hdl.handle.net/2134/27484. 
Appetite for or resistance to consumption relationships? A trans-European perspective on the marketization of football fan relationships

Guillaume Bodet, James A Kenyon and Alain Ferrand

\title{
Guillaume Bodet
}

Univ Lyon, Université Claude Bernard Lyon 1, L-VIS, France

School of Sport, Exercise \& Health Sciences, Loughborough University, UK

\section{James A. Kenyon}

School of Sport, Exercise \& Health Sciences, Loughborough University, UK

\author{
Alain Ferrand \\ Centre de Recherche en Gestion (CEREGE - EA 1722), Faculty of Sport Sciences - \\ University of Poitiers, Fr
}

Corresponding author

Guillaume Bodet, L-Vis, UFR STAPS Lyon 1, 27/29 Bd du 11 Novembre 1918, 69622 Villeurbanne Cedex, France

\begin{abstract}
Although most sport organisations are encouraged to better manage the relationships they maintain with fans, little is still known about the types of relationships that fans want to establish with sport organisations. Also, as most suggested management and marketing practices come from professional sport organisations and European contexts, it is questionable whether they can apply to all sports organisations, and whether they are received in the same way by diverse fans from various socio-cultural contexts. Thus, the study aimed to explore football fans' relational expectations towards their national football association
\end{abstract}


across Europe and attitudes towards this marketization. Focus groups and individual interviews were conducted with several casual and die-hard fans from three European countries chosen for their heterogeneity: Armenia, Lithuania and England.

Overall, and possibly in contradiction with numerous publications dealing with club football, the fans from the three countries did not express clear opposition or resistance towards the marketization of their relationships towards their national teams and associations. English fans seemed quite neutral or indifferent although Armenian and Lithuanian fans presented many characteristics of brandom demonstrating an appetite for this marketization.

Keywords: commodification, fans, football, relationships, organisations

\section{Acknowledgements}

The authors would like to thank UEFA for supporting this study through the UEFA Research Grant Programme, Noel Mooney for his help and advices, Edvinas Eimontas for his support to the project, and Andrius Pacevičius and Amalya Grigoryan for their valuable contribution to the data collection process. This project was funded by UEFA but neither the results nor the commentaries are UEFA's responsibility and remain the sole responsibility of the authors. 
"Consumption is an active mode of relations (not only with objects, but with the community and the world), a systematic mode of activity and of global response upon which our entire cultural system is based" (Baudrillard, 1968)

\section{Introduction}

Since the early 1990s football has experienced substantial changes to its financial aspects and cultural organisation that have significantly impacted its stakeholders, including: players, spectators, and media commentators (Giulianotti, 2002; Nash, 2000). Although this move away from the game's traditional, working-class cultural heritage and roots (e.g. Duke, 2002 ; Hognestad, 2012) and toward a more commercially-oriented structure was first observed in England in the 1960s (Taylor, 1971), the financial and cultural transformation of professional football across Europe, has accelerated exponentially. Clubs, and their governing organisations, have progressively and increasingly adopted a range of business- and consumer-oriented practices, and media and marketing strategies, both through, and by way of, the corporatisation of professional football: i.e., 'the prioritizing of profitability [...] over its historical, cultural, social or aesthetic elements' (Walsh \& Giulianotti, 2001, p.55).

Meanwhile, relationship marketing has been observed, analysed and/or recommended by many marketing management experts (e.g. Christopher, Payne, \& Ballantyne, 1992; Grönroos, 1994) since the nineties as the most relevant approach to respond to consumers' needs and expectations, and to enhance firms' and organisations' sustainability. This supposedly new philosophy or strategic orientation relies on two main assumptions. First, that it is less expensive to keep current customers than attracting new ones as it reduces administration and marketing costs (e.g. Mahony, Madrigal, \& Howard, 1999) and encourages current customers to purchase more often or pay more, and provides benefits in 
terms of consumer behaviour and human resource management (e.g. positive word-of-mouth, advocacy, customer voluntary performance). This legitimates the use of the relationship marketing approach from an organisational perspective. The second, which legitimizes it from a consumer perspective, sees consumers as preferring on-going and sustainable relationships with organisations, rather than continually switching.

Following this relationship trend, the commodification of sport (Giulianotti 2005), and the development of brandom trends - defined as 'brand-controlled fan communities that lack real autonomy' (Guschwan 2012, p.19) -, sport organisations, whether they are for profit or not, increasingly try to actively manage their relationships with their publics. However, these management approaches and techniques are often implemented without having previously defined what kind of relationships various segments of their publics want to establish with them, and thus organisations often develop practices that are too organisation-focused (Adamson, Jones \& Tapp 2006).

Furthermore, anecdotal and scientific evidence tends to show that sport fans, and particularly football fans, are often sceptical and sometimes resistant to the marketing management rhetoric (Numerato, 2015); an approach which considers them as customers and no longer as fans (e.g. Oppenhuisen \& van Zoonen, 2006). Consequently, before conceptualizing what Adamson, Jones, \& Tapp (2006) called Fan Relationship Management, it becomes necessary to first define the types of relationships fans perceive and aim to establish with sport organisations. Specifically, this study first aims to challenge one foundational relationship marketing assumption and determine whether fans necessarily want to establish relationships and for those who display such appetite, whether the proposed relational formats are appropriate. Furthermore, considering the strong focus of the academic literature on 
professional leagues and clubs, and the growing adoption of relationship marketing approached by national football associations (UEFA, 2015), we aim to focus on the links between fans and their national teams (NTs) and associations (NFAs).

Although these managerial recommendations often tend, consciously or not, to consider consumers as universally similar, it is erroneous to consider that varying historical, socioeconomics, cultural contexts, and forms of football commodification (Ben Borat, 2012), will facilitate the same kind of expectations and relationships between football fans and organisations. Moreover, since the literature has mainly focused on commodification impacts within single cultural contexts, this study aims to investigate whether the appetite for, or resistance to, these relational approaches and their receptions vary according to diverse European national contexts, to further explore if historic, socio-economic and cultural features shape national football fans' consumption.

\section{The commodification and commercialisation of football}

Football has undergone dramatic commodification (termed, hyper-commodification) 'in societies structured around global capitalism,' evident, for example, 'in the sale of television rights for matches in the most popular leagues' and the soaring salaries of the game's star players (Hognestad, 2012: p.377). This vast transformation in the financial and cultural organisation of football has resulted from, among other developments: the 'gentrification' of football stadiums throughout the 1960s (Taylor, 1971), increases in advertising and sponsorship opportunities throughout the 1970s (Andreff \& Staudohar, 2000), the increasing importance of broadcast rights throughout the 1980s leading to the establishment of the English Premier League in 1992, thus consolidating the link between football and mass media (Fürtjes, 2014), the expansion and diversification of global supporter-bases throughout the 
noughties (e.g. Giulianotti \& Robertson, 2004), the sponsorship and merchandising opportunities resulting from these newly-established international links alongside the proliferation of new media (Santomier, 2008), and the influx of wealthy owners from around the world (Millward, 2013). The concurrent and resulting professionalization of the football industry has changed the way in which clubs, but also NFAs and supporters interact, with the former taking a much more market-based approach to managing their relationships.

As professional football's commercialisation has progressed, so supporters have increasingly come to be labelled by clubs, governing organisations, and broadcast media, as 'customers' and 'consumers' (Oppenhuisen \& van Zoonen, 2006). Being identified in such a marketfocused way has drawn 'potent' criticisms from supporters (Giulianotti, 2005), who perceive such categorisations as emphasising 'the consumption of football through expertly targeted merchandising that exploits communal identity, and the adoption of an exorbitant pricing policy for watching football, both in terms of matchday tickets and of pay-per-view broadcasting' (Kennedy \& Kennedy, 2012, p.330). At the root of these criticisms is what Giulianotti $(2002,2005)$ describes as football's contemporary 'commodification' - or, its hypercommodification -, which, in the relevant literature, refers to the process by which something that has not previously had an economic value becomes valuable and subject to market rules (Akindes, 2013). The subsequent hypercommodification of football has left supporters 'to experience their club and its traditions mostly through the purchase [or consumption] of replica tops and a variety of other club merchandise, alongside subscriptions to commercial TV channels and websites streaming live games with their club' (Hognestad, 2012: p.381). 


\section{Branding and relationship management}

A more recent expression of this commodification of football - and of the progression of the market logic - considers the management of the links that sport organisations establish with their fans and followers. This approach, which assumes that sport organisations should be considered and managed as brands (Bouchet, Hillairet, \& Bodet, 2013), increasingly aims to import modalities and techniques used in other industries to manage their customers. This is true of customer relationship management (Adamson et al., 2006). However, the application of these techniques in the football industry has very often lacked adaptation to the specificities of football, and sport in general, and the particularities of the links sport organisations establish with their fans and followers (Adamson et al., 2006). Furthermore, despite 'talking the talk' of relationships, which should see organisations and fans as longterm, trustworthy and committed partners aiming for mutual benefits, most professional clubs 'walk the walk' of transaction marketing that focuses on one-sided short-term benefits, creating resentment among many supporters who perceive this as a commercial intrusion in their relationship with their club (Adamson et al., 2006). This fits with Guschwan's (2012) work that made a distinction between 'fandom' and 'brandom' for whom, the former is the opposite of the latter and, even if fandom is not free from acts of consumption, goes beyond the simple consumption of sport games and brands' by-products, and relies on a strong participatory and subversive culture (Guschwan, 2012). Based on these definitions, it can be expected that brandom tends to embrace commodification and the branding logic, while fandom tends to waiver between compliance and resistance (Guschwan, 2012).

\section{Receptions of branding and relationship management}

Although Harris \& Ogbonna's (2008) findings support a more diverse and more complex view of relational dynamics between football fans and their clubs, they also support these 
grand categories, namely club-connected fans and die-hard fanatics, with the former corresponding to brandom and the latter to fandom. Club-connected fans present a deep emotional tie with their club, are amenable to the club's effort to develop links, and therefore respond favourably to initiatives aimed at maintaining and enhancing these relationships (Harris \& Ogbonna, 2008); they "tend to conform to the prescriptions often advocated in the managerial literature of relationship-oriented consumers" (p. 395). Although, die-hard fanatics share the same, and sometimes stronger, deep emotional link, they focus on the team, and tend to reject the club's efforts to strengthen the relationship and favour links with likeminded fellow supporters and self-directed communities (Harris \& Ogbonna, 2008). This demonstrates that the divide is not then between relational seekers and transaction seekers, but between fans who praise commodified and market-framed strategies and those who do not.

Strong similarities can be found with the work of Giulianotti (2002) who already distinguished fans based on a traditional-versus-consumer spectrum where "traditional spectators will have a longer, more local and popular cultural identification with the club, whereas consumer fans will have a more market-centred relationship to the club" (p.31). However, this author added a second hot-cool axis, reflecting "the different degrees to which the club is central to the individuals' project of self-formation" (p.31) and, consequently, forms of participation and interaction with the clubs. When combined, these axes create four categories of ideal types - supporters, followers, fans, and flâneurs, demonstrating the variety of relationships individuals have with sport organisations. Beyond the diversity of relationships, Hewer, Gannon \& Cordina (2016) demonstrated that for some supporters, the relationships their club establish with fans contradicts with their passions and beliefs, inciting them to develop counter-identities and resistances, making them brand agitators or rebels, 
although centred towards the same object. Many contemporary examples of fans' resistance to the marketization of relationships can be observed to various degrees of manifestation and reception in European sport (Chanavat \& Bodet, 2014; Numerato, 2015). From a spectator/fan perspective, it was found that the proposed entry of market rhetoric, illustrated by the use of terms such as 'customer' and 'branding' and the market-centred differentiation (i.e., supporters versus fans), was seen as controversial, and some fans fear losing a part of their identity and culture (Duke, 2002; Giulianotti, 2005; Oppenhuisen \& van Zoonen, 2006).

\section{Contextualised forms and consequences of football commercialisation}

Although the numerous impacts on supporters, resulting from the commodification of the game and brands' commercialisation activities, have been the subject of considerable academic attention in recent years (e.g. Ben Borat, 2012; Giulianotti, 2005; Kennedy, 2012), they have remained focused on a few European countries, particularly from Western Europe. However, as Ben Porat (2012) argues, “the process of football's commodification in various countries is similar to the process of becoming a capitalist society, yet it is also formulated by the specific characteristics of the particular society" (Ben Porat, 2012: pp.444-445).

Consequently, it appears important to embrace the variety of football and economic contexts in studying commercialisation impacts on supporters and fans, considering the strong sociohistorical and economic differences between European contexts. This is exemplified by the following quote: "[... smaller European football nations] clubs and leagues are competing at a considerably different level than the rest of Europe, both commercially and competitively, the findings from previous research might not necessarily be applicable to clubs competing in the smaller European football nations" (Abosag, Roper, \& Hind, 2012, p.1234). From a theoretical perspective, this approach fits with Askegaard \& Linnet (2011) who regretted the excessive emphasis on individual projects in Consumer Culture Theory (CTT), and therefore 
called for a more contextually (socially, culturally, politically, and institutionally) oriented CCT (p.384).

With the above in mind then, it seems therefore justified to investigate the nature of relationships between fans and sport organisations in various contexts. Furthermore, although most of these studies were conducted in the context of professional football clubs, and focusing mainly on fans demonstrating a strong loyalty to their club - also known as die-hard fans -, it can be assumed that these issues are fully applicable to the context of NFAs and NTs because such organisations increasingly employ management and marketing rhetoric (Bouchet et al., 2013). And, for instance, we could wonder whether they could be amplified in NFAs' context due to the importance of national identity and symbolism. Consequently, this study's overall aim was to identify whether fans want to establish a relationship with their NFAs in the context of international European football, and demonstrate an appetite for, or, on the contrary, a resistance to, their marketing and relationship management practices.

\section{Methodology}

Consistent with our objectives, we adopted an inductive research approach relying upon focus groups and individual interviews. These methods seemed the more appropriate for accessing the complexity, diversity, and dynamics of perceptions and opinions, and was previously advocated by Harris \& Ogbonna (2008) who analysed the relationships between English fans and their clubs. As previously discussed, the search for relationships, and consequently their appreciations, are not homogenous among fans, and it was therefore important to grasp this diversity (Giulianotti, 2002; Numerato, 2015). Although many relevant variables and approaches have been used to classify sport fans (see for instance Bodet \& Bernache-Assollant, 2012, for a review), due to practical aspects regarding fan 
selection, we decided to focus on behavioural aspects rather than relying on frameworks based on psychological and sociological variables, and multiple criteria. We thus adapted Tapp \& Clowes' (2002) classification to distinguish between two broad categories, namely die-hard, that corresponded to the Fanatics from Tapp and Clowes' nomenclature, and casual fans, that gathered regular and casual fans in the same nomenclature. This categorisation was based on their level of loyalty, measured via the number of games attended in a year. As the league context and the number of games from Tapp and Clowes (2002) were not equivalent to our contexts, fans physically attending more than 2 games per year and/or watching more than half of the televised games were used as guidelines to allocate fans into groups. However, they were not used as strict exclusion criteria, and fans' self-classification was also considered when it was not obvious following the former criteria. Although interviews and focus groups' proceedings confirmed the relevance of the classification, this approach is not free from limitations and criticism.

In line with Askegaard \& Linnet (2011), who "argue for the legitimacy of thinking in collective subjects" (p. 387), and consequently support the combination of grounded observations and more structural issues, and the various studies on commodification process in sport, we considered that the sporting, cultural and socio-economic contexts would influence these perceptions, and that it would be relevant to compare whether the phenomena at stake differed between European countries. Consequently, three countries, namely Armenia, England and Lithuania, were chosen for the case study. The number of countries was based on pragmatic issues, such as the resources involved, and the capacity to collect the data; it was not our intention to present these countries as being either 'enough' or fully representative of the larger European group. 
Consistent with our inductive approach, we aimed for countries with significant differences in terms of geographic location within Europe, the performance of their NTs, the strength of their domestic football league, and overall economic development (see table 1 in Appendix). These countries are not located in the same parts of Europe (west, north and east) and they present different economic developments, with England, as part of the United Kingdom, being the wealthiest and presenting the highest human development index among the three. Being the birthplace of modern football, this is the most popular sport in England. It appears to be the most popular team sport in Armenia, although it is second to basketball in Lithuania. In England, the NT is facing competition for fans' hearts and expenditure from club football, although the club game is not as well developed in Lithuania and Armenia1. Although these represent the most evident distinctive characteristics in relation to the research topic and questions, it certainly does not represent all of them.

A semi-structured interview guide was developed and comprised of four main sections, with this format allowing the interviewers to further probe and scrutinise the participants' feelings, perceptions and opinions relating to the aim of the research (Ayres, 2008). The first section of this interview guide dealt with the relationship between the fans and NTs, and included questions such as 'how often do you seek information about your football NTs?', 'do your feel your NTs to be close to you?', 'how would you qualify the relationship you have with the NTs and their players?', and 'are you happy about these relationships?'. The second section dealt with the relationships between the fans and their respective NFAs. The questions were similar to those from the first section but involved the NFA instead of the NTs and players. The third section dealt with the NFA's communication and marketing practices and included questions such as 'do you know what the NFA is doing in terms of communication and

\footnotetext{
${ }^{1}$ These contextual elements were provided by our partners from the local national football associations.
} 
marketing (e.g. ticketing, merchandising, etc.)?', 'do you feel concerned or targeted by these actions?', 'do you feel connected with the NFA's members?', and 'do you feel part of the same community?'. Finally, the fourth section dealt with the comparison between the NFA and domestic club football and comprised questions such as 'if you follow club football, how would you compare the relationship you have with your local club and the national team and association?', 'generally speaking, what do you think about the marketing of the domestic club you support?', and 'would you like the NFA to do similar things?'.

For Armenia and Lithuania, two focus groups were gathered and conducted by partners from the local NFA, after being briefed by the authors. Following Grover \& Vriens (2006)'s recommendations, we aimed for between 6 and 10 participants per group. Consequently, the focus groups comprised 11 and 8 die-hard fans per group and 11 and 8 casual fans respectively for Armenia and Lithuania. Because of the strong rivalry between football clubs and fans in England, individual interviews were chosen for this context and concerned 6 casual and regular fans and 4 die-hard fans. The number of individual interviews was determined based on the semantic saturation criterion (Grover \& Vriens, 2006). Although, the mix of individual interviews and focus groups were deemed relevant to the contexts of each country, this mix can represent a limitation. Another limitation could concern the composition of each focus group that mainly gathered young males (11 females out of 47 fans) and, even if they do represent the majority of NTs' fans of these countries, they are not representative of the spectrum of fans. Considering the differences between male and female fans (e.g. McDonald, Leckie, Karg, \& Zubcevic-Basic, 2017), this represents an important research perspective. 
The four focus groups and ten semi-structured interviews were all audio recorded and transcribed. Upon completion, these transcripts were then uploaded to and managed using the qualitative research software QSR NVivo. A thematic analysis was then conducted on the transcripts in which patterns were identified, and then categorised into themes. Specifically, and informed theoretically by Braun \& Clarke (2006), this initially involved the three researchers reading and re-reading the transcribed interviews and focus groups to become familiar with the data, followed by the separate generation of some initial codes that identified segments of the data as significant. Following post-hoc consultation between the researchers concerning the content and designation of these initial codes, emerging themes were then agreed upon and documented, and later organised into meaningful categories. Through undertaking this analysis, two broad themes were identified, marketization and relationships, with sub-themes also being identified within the latter: nature and appetite.

\section{Nature and Appetite for relationships}

Interestingly, the majority of fans do not perceive they have an active relationship neither with the NTs nor with the NFAs, irrespective of the countries at stake. These fans acknowledge sporadic contact, but talk about "cold", "non-existent" and "inactive" relationships, which seems quite similar to what was previously observed in club football (Adamson et al., 2006). Only very few fans do acknowledge special relationships, but mainly because of the personal relationships they have with certain senior or youth players, staff and members of the NTs and NFAs, and that are due to circumstances and not structures. However this absence of relationship does not have the same impact on fans, particularly the die-hard ones. Several casual fans consider this situation as normal, without having clear and specific expectations about it. One Lithuanian casual fan said: 
"I would describe my relationship as a normal fan's. I always take interest in what the federation is doing, follow the news and actively discuss them with my friends. I watch, take interest but I do not think I have a direct relationship".

Interestingly, the directness of interactions and contacts appears here a key factor to define what is a relationship.

The sporadic contacts mentioned above are those around the games and are therefore closely linked to the cycle of international football fixtures and tournaments. However, several England fans maintain contact with many of the NT's players through club football, which was not the case for Armenian nor Lithuanian fans. Although NTs are at stake, the players dimension appears central to the characterisation of the nature of the relationship fans can have and perceive. This is a common feature across the three countries studied and in line with the analysis of Rojek (2001) for whom the commodification of everyday life is one of the drivers of a celebrity culture- potentially explaining this growing interest and focus on individual players. Particularly, in both Armenia and Lithuania, fans seem to consider that individual players 'do not do enough', mainly because they do not really want to. This issue is also expressed among English fans who explained that they had no feeling of closeness to the players, even for those who did express interests in players, and consequently no feeling of close relationship. This lack of closeness is partly explained for England fans by players' belonging to teams that fans do not support indicating that attachment to club football can alter national identification and ties.

Moreover, this absence of closeness is explained by a growing distance between fans and players' earnings and lifestyle. This is expressed as follow by one England fan: 
"I feel that a lot of the players are (...) a little bit socially removed from the common man in this country. (...) And because of that, that sort of weakens the link between myself (and England), and probably (for) a lot of other fans too. So a lot of people probably feel slightly alienated from a lot of the players. Not all of the players, but a lot of the players. (...) I think the root of it is that they earn such a large amount of money compared to the working man... the average man".

This growing distance often observed at club football level, is interesting to observe at the NT level, although NFAs are not directly responsible for players' earnings. Players' earnings and lifestyles can be considered a consequence of commodification processes, and even if players can be local, and play in the local league, they are increasingly seen as distant stars and celebrity brands, rather than people from the fans' community. Spectators' gentrification is a key characteristic of football commodification (Williams, 2006), but players' perceived gentrification and lifestyle seem also important to explain the lack of attachment towards English players, irrespective of the level of loyalty fans demonstrate.

This situation can appear quite paradoxical as, on one hand, players are increasingly seen as over-rich celebrities while fans regret their lack of involvement and sometimes professionalization in their communication, which can also be seen as a feature of the marketization of their image and personal branding (Dumont, 2017).

However this disregard for what can be interpreted as a commodification's consequence in England was not observed in Armenia and Lithuania where domestic players earn far less and club football is not as developed nor professional. On the contrary, many of these fans would like more relevant information to be filtered through social media - which can be explained by the fact that most of them are quite young - in the fashion of player-brands like Cristiano Ronaldo (sic), although some England fans praise players from their local football club who are seen as more 'friendly' and 'approachable'. 
For many of them, this strong fluctuation in contacts could be diminished through the use of social media that create more regular interactions similarly to what can be done with professional football clubs. These results indicate that, even if it is not enough to create a relationship, contact frequency is key for most casual and die-hards fans. Contact and communication frequency was identified as an intensifier of relationships in the service context (Dagger, Danaher, \& Gibbs, 2009) and attachment to sport organisations in particular (Funk \& James, 2006). This was even more the case for fans from Armenia and Lithuania, as the expectation that players might fill the void of the absence of a relationship with domestic club football, and the irregularity of contacts with the NT. Their appetite for more contacts display strong similarities with 'club-connected fans' identified by Harris \& Ogbonna (2008). One particular situation is the one of organised die-hard fans from Armenia who wanted to be close, but concurrently independent. On one hand, this can be explained by a non-desire to create links with institutions but players as the 'fanatics'(Harris \& Ogbonna, 2008). On the other hand, it can be explained by the personality of the NFA representatives, and particularly the chairman. However, they want to have direct communication and a relationship that would cater for their needs that focus on players. Strong similarities can be observed in this context with club football fandom (Guschwan, 2012), and we can wonder if this structuration, around the NT, and type of close relationship is not the consequence of the absence of strong club football in Armenia as a focus of interests and attachment.

Unlike the previous case of Armenia, few fans from Lithuania and England do not expect to have a close relationship with the NT and the reason seems that they already have a close and personal relationship with the football club they support. This echoes one question raised by one interviewee from Lithuania about the mere possibility of creating regular contacts, and consequently deeper relationships, with the NT. In this situation, fans do look for close relationships, but not with the NT. This is mainly due to the fact that such fans cannot see 
themselves as having two close relationships at the same time. This is different from what was previously expressed by several die-hard fans who do not express the desire to have strong relationships, because they "like relationships that don't tie them down".

For most casual fans who believe it is possible, and duly desire a closer relationship, the absence of relationship is mainly due to a lack of communication and interaction, which is justified by many of them by a lack of motivation and enthusiasm from the NFA. This communication issue is reported by numerous fans but does not seem to be the sole reason. One English respondent said: “there is no passion towards it, I guess. That's a massive difference, there's passion towards England team, but not towards the FA at all". This absence of passion seems often related to a lack of knowledge and awareness of the football associations' identity and actions, in general and specifically in relation to the NTs. This is also related to the not-so-appealing image NFAs can have. They are not seen as wellgoverned and transparent organisations, and hold a traditional and sometimes an 'old-men' organisational image based on cronyism. The importance of the NFAs' image seems particularly important for casual fans that mainly get information through the media and when negative events and scandals are reported. The importance of the governance issue echoes the increasing concerns regarding the principles of good governance (Geeraert, Alm, \& Groll, 2013) and social responsibility (Breitbarth \& Harris, 2008) of sports and football organisations. For instance a couple of Lithuanian fans said they would not want to take part in NFAs' activities and grassroots projects because the organisation was not deemed trustworthy enough; a lack of trustworthiness often being a lack of transparency and accountability. Image can also play a role in linking fans and NTs, as one fan said that connections can exist come from relating to a player's qualities, style of play, and mental attitude. However this may also have some limitation considering the growing perceived distance between players and fans previously discussed. 
Regarding the feeling of community, most casual and die-hard fans from the three countries did not perceive a strong belonging. Many of them did feel part of the football community in a broad sense but without strong ties towards the other members. As one Lithuanian fan said: "I do feel part of the football community but more in a passive way". To increase this feeling of community, more personal attention could be the solution. However, club and national football communities were not seen as distinct and for several of them they could be better imbricated. Mainly for Lithuania and England, the relationships with clubs were not necessarily more important, but seen as better, because they were closer and more regular.

\section{Attitudes towards marketization}

Although many publications have demonstrated and focused on the increasing resistance of fans towards club football commodification (e.g. Giulianotti, 2005; Numerato, 2015), such feelings were not clearly expressed for NTs and NFAs. On the contrary, numerous fans demonstrated an appetite for marketization having specific expectations regarding marketing platforms and techniques. Many fans noted a lack of involvement and efficiency in communication and marketing campaigns, and expected more promotion, advertising, and publicity, as exemplified by the following quote from a Lithuanian casual fan: "I think the federation should invest much more into advertising and spread of information to spread it much wider than just their official web page". This comment epitomises what many fans thought in all three countries in terms of communication.

However, even basic tools such as a regularly updated websites and newsletters would also be welcome, with some personalisation or emphasizing of the topics that fans are interested in. This underlines the importance of personalisation, which is also a characteristic of relationship marketing. 
Nevertheless, quality, as much as quantity, and defined as a "two-way or multiway communication (...) through a mediated channel” (Kiousis, 2002) (p. 368), seems to be of great importance and interactivity, and was mentioned on many occasions. This corresponds to the principle of relationship marketing, which is based on a dialogue between partners (Christopher et al., 1992). And as much as wanting information, fans want to be consulted of the information provided. For example, as one Lithuanian fan stated:

"The federation could take more interest in the opinions of people interested in football; especially by doing various surveys. With the feedback they should respect it and after evaluation should apply solutions to solve issues". This echoes the previous appetite for social media that are generally seen as (more) interactive communication tools.

This willingness to be a partner is not a unique phenomenon and corresponds to what is seen in many areas of consumption where consumers want to become prosumers (Ritzer \& Jurgenson, 2010). This prosumer role, which was the most salient for the organized die-hard fans from Armenia, is also supported through comments asking for more cooperation and collaboration roles, with some even talking about watchdog role. However, with reference to the loose feeling of community they expressed, we interpret that the active role they want to exert is still understood in a dyadic relationship type (them - the organisation) rather in a brand community sense (Hewer et al., 2016), where links between members are as strong as those with the brand.

Also, they expect more events, more activities, and consistent with above, more contacts to create a stronger link with both the NTs and NFAs. One Lithuanian fan illustrates this stating that "there is a lack of events that involve communities and the public into football - like family football tournaments and other similar events". 
In terms of marketing, numerous fans from Armenia and Lithuania complained about the products and merchandising because they would not know where to buy replica shirts if they wanted to. Beyond the simple mere expression of consumption and possession, the symbolic dimension (Baudrillard, 1970), seemed central to them. Also, the products were linked by one Armenian fan to national identity and pride stating:

"There are very few attributes symbolising our football and our national team, while there could be many different things, such as cups, pens, towels, balls, etc."

All issues related to marketing were discussed and commented on almost in the same fashion in Lithuania and Armenia. Some fans said that they wanted to see more animations during games such as contests and attractions, corresponding to experiential marketing approaches that aim to enrich ordinary experiences by providing more activities (Chanavat \& Bodet, 2014). Furthermore, several fans complained about the tickets' price, which can be in contradiction with the desire to have enriched game experiences. This type of ambiguity among fans was previously noticed by Numerato (2015).

One difference was noted in relation to marketing with England fans who could only identify aspects related mainly to sponsors. However, this awareness did not translate into any particular attitudes or comments, rather scepticism as expressed in the following statement: "I am not really attracted by it. (...) I'm not really going to say, 'Joe Hart's wearing an England shirt, and he's wearing those gloves, and playing with that football, I should buy that.' (...) none of that is going to work on me". 
This quote and other comments indicated that several fans were aware of these issues but expressed some indifference, possibly explained by the high exposure to marketing and sponsorship. Surprisingly, however, none of the English fans manifested clear upset or anger towards these aspects of national football. This statement seems to contradict the expressions of Armenian and Lithuanian fans who displayed some kind of appetite for it.

Ticketing was the other marketing dimension noticed by England fans. There were few feelings expressed about over-pricing, but also an acknowledgement that the NFA was quite aggressive about it, sending a lot of emails before the games, but also a feeling that a good job was done regarding this issue, almost as if aggressive marketing was accepted in the present day and a sign of good marketing. Linking ticketing and sponsorship, however, one commented on the fact too many corporate tickets are sold, causing too many empty seats, negatively affecting the atmosphere, which was 'terrible'. Higher ticket prices and the corporatisation of football crowds are two features of the commodification of football and we can see here that few fans in England express gentle dislike and not strong opposition.

\section{Conclusion}

Attempting to extract summarising patterns through heterogeneous contexts and discourses always represents a complicated exercise. However, its seems to us that fans' loyalty was not as structured as we would have expected in each country, nor were the supposed differences between casual and die-hard fans as bold. On the contrary, we sometimes found more divergences of opinion within than between fan groups. For instance casual fans could be distinguished between those, a minority, who did not search for close and deep relationships with their NTs and NFAs, and those, the majority, who seek for more. The same divide appears among die-hard fans but for various reasons, and with most die-hard fans from 
Armenia and Lithuania looking for further contacts to the difference of England's die-hard fans.

In terms of consumption relationships however, it is interesting to note the similarities between these three different contexts. Particularly with regards to the drivers of what fans perceive as strong relationships, frequency of interactions, interactivity, personalisation, trustworthiness, and proximity, which were identified as common factors. In regard to the latter, it is interesting to observe that one among the very few England fans who preferred supporting England over his club cited geographical distance to a football club to explain this hierarchy, while this is the same situation for Armenian fans.

Overall, the fans from the three countries did not express clear opposition or resistance towards the marketization of their relationships towards their NTs and NFAs. English fans seemed quite neutral or indifferent, while Armenian and Lithuanian fans presented many characteristics of brandom, demonstrating an appetite for this marketization. This result can possibly be explained through Anderson (2006)'s definition of nations as imagined communities, in the sense that social ties and physical contacts are weaker than in local communities, and consequently not strong enough to produce resistance.

Consistent with a contextually oriented analysis of consumer culture (Askegaard \& Linnet, 2011), our findings support the need to investigate the commodification of football and marketization, and its translation for organisations and publics, from various perspectives. First, commodification does not only concern club football and that national football is also concerned with the phenomenon, confirming Baudrillard's (1968) quote regarding the nature of consumption, that characterizes a rapport to the world and not only a rapport to certain objects and commodities. Despite identity, symbolic and national ties, most casual fans we surveyed wanted to establish 'normal' consumption relationships as those designed and 
promoted by marketing and relationship management techniques, and experts. Obviously, some casual fans did not express the will to establish particular relationships with NTs and NFAs, and some even questioned the possibility of doing so, though they did not explicitly oppose, or express resistance. Consumer culture does not seem to always foster feelings of rebelliousness, as suggested by Illouz (2009). It can certainly create these feelings (Giulianotti, 2005; Oppenhuisen \& van Zoonen, 2006) but for certain type of fans, and in certain contexts. In this case, the great majority of fans from Armenia and Lithuania, which are not as developed and commodified societies as England, expressed an appetite for more marketized relationships. One could argue that media play a strong role in creating a dreamed or simulated representation (Debord, 1967) of what relationships between fans and sport organisations should be, but, meanwhile, one could argue that marketplaces represent the current crucible where consumers can manifest their individual and collective identity projects (Hewer et al., 2016; Numerato, 2015).

Within the former view, this appetite for marketization could be seen as an early step in the consumption culture cycle, and that when further advanced in this cycle, Armenian and Lithuanian fans will become more rebellious as Illouz (2009) suggested. However, this would not fully explain why not all English fans do not demonstrate resistance towards marketization. At most they showed dislike but mainly indifference. Within the latter view, this can be seen as the result of particular contextual cultural, historic, economic and sporting factors whose complexity does not allow for predicting the future shaping of individuals' attitudes and behaviours. For instance, the absence of professional leagues, the dominance of other sports, and geo-political situations, could contribute to explain such perceptions and attitudes, reinforcing the need to imbricate the micro level of lived experiences, and the macro socio-cultural contexts (Askegaard \& Linnet, 2011) to further understand consumer culture in relation to football and sports. Consistent with this last approach, it appears logical 
to us to follow this study with a trans-national survey with fans to further investigate these differences and try to combine a deep understanding of 'vertical' differences within fans of the same country and 'horizontal' differences associated to the diversity of national and cultural contexts to better apprehend football consumption.

\section{References}

Abosag, I., Roper, S., \& Hind, D. (2012). Examining the relationship between brand emotion and brand extension among supporters of professional football clubs. European Journal of Marketing, 46(9), 1233-1251.

Adamson, G., Jones, W., \& Tapp, A. (2006). From CRM to FRM: Applying CRM in the football industry. The Journal of Database Marketing \& Customer Strategy Management, 13(2), 156-172.

Akindes, G. A. (2013). South Asia and South-East Asia: new paths of African footballer migration. Soccer \& Society, 14(5), 684-701.

Anderson, B. (2006). Imagined communities (Revised edition). London and New York: Verso.

Andreff, W., \& Staudohar, P. D. (2000). The evolving European model of professional sports finance. Journal of Sports Economics, 1(3), 257-276.

Askegaard, S., \& Linnet, J. T. (2011). Towards an epistemology of consumer culture theory: Phenomenology and the context of context. Marketing Theory, 11(4), 381-404.

Ayres, L. (2008). Semi-structured Interview. In L. M. Given (Ed.), The Sage Encyclopedia of Qualitative Research Methods (pp. 810-811). Thousand Oaks, CA: Sage Publications.

Baudrillard, J. (1968). Le système des objets. Paris: Gallimard.

Baudrillard, J. (1970). La societé de consommation (Folio/Essais). Paris: Denoël.

Ben Borat, A. (2012). From community to commodity: The commodification of football in Israel. Soccer \& Society, pp. 443-457.

Bodet, G., \& Bernache-Assollant, I. (2012). Sport spectators' segmentation. In L. Robinson, P. Chelladurai, G. Bodet, \& P. Downward (Eds.), Routledge Handbook of Sport Management (Vol. Routledge International Handbooks, pp. 254-266). Abingdon, Oxon, UK: Routledge.

Bouchet, P., Hillairet, D., \& Bodet, G. (2013). Sport brands. Abingdon, Oxon: Routledge.

Braun, V., \& Clarke, V. (2006). Using thematic analysis in psychology. Qualitative Research in Psychology, 3, 77-101. 
Breitbarth, T., \& Harris, P. (2008). The Role of Corporate Social Responsibility in the Football Business: Towards the Development of a Conceptual Model. European Sport Management Quarterly, 8(2), 179-206.

Chanavat, N., \& Bodet, G. (2014). Experiential marketing in sport spectatorship services: a customer perspective. European Sport Management Quarterly, 14(4), 323-344.

Christopher, M., Payne, A., \& Ballantyne, D. (1992). Relationship marketing: Bringing quality, customer service and marketing together. Oxford: Butterworth-Heinemann.

Dagger, T. S., Danaher, P. J., \& Gibbs, B. J. (2009). How often versus how long the interplay of contact frequency and relationship duration in customer-reported service relationship strength. Journal of Service Research, 11(4), 371-388.

Debord, G. (1967). La société du spectacle (Vol. 3e édition). Paris: Gallimard.

Duke, V. (2002). Local tradition versus globalisation: resistance to the McDonaldisation and the Disneyisation of professional football in England. Football Studies, 5(1), 36-42.

Dumont, G. (2017). The Beautiful and the Damned. The work of new media production in professional rock climbing. Journal of Sport \& Social Issues, online, 1-9.

Funk, D. C., \& James, J. D. (2006). Consumer loyalty: The meaning of attachment in the development of sport team allegiance. Journal of Sport Management, 20(2), 189-217.

Geeraert, A., Alm, J., \& Groll, M. (2013). Good governance in international sport organizations: An analysis of the 35 Olympic sport governing bodies. International Journal of Sport Policy and Politics, 6(3), 281-306.

Giulianotti, R. (2002). Supporters, Followers, Fans, and Flâneurs: A Taxonomy of Spectator Identities in Football. Journal of Sport and Social Issues, 26(1), 25-46.

Giulianotti, R. (2005). Sport spectators and the social consequences of commodification: Critical perspectives from Scottish football. Journal of Sport and Social Issues, 29(4), 386410 .

Giulianotti, R. (2011). Sport mega events, urban football carnivals and securitised commodification: the case of the English Premier League. Urban Studies, 48(15), 3293-3310.

Giulianotti, R., \& Robertson, R. (2004). The globalization of football: a study in the glocalization of the 'serious life'. The British Journal of Sociology, 55(4), 545-568.

Grönroos, C. (1994). Quo Vadis marketing? Toward a relationship marketing paradigm. Journal of Marketing Management, 10(5), 347-360.

Grover, R., \& Vriens, M. (2006). The handbook of marketing research: Uses, misuses, and future advances. Thousand Oaks, CA: Sage Publications. 
Guschwan, M. (2012). Fandom, brandom and the limits of participatory culture. Journal of Consumer Culture, 12(1), 19-40.

Harris, L., C., \& Ogbonna, E. (2008). The Dynamics Underlying Service Firm-Customer Relationships. Insights From a Study of English Premier League Soccer Fans. Journal of Service Research, 10(4), 382-399.

Hewer, P., Gannon, M., \& Cordina, R. (2016). Discordant fandom and global football brands: 'Let the people sing'. Journal of Consumer Culture, 0(0), 1-20.

Hognestad, H. K. (2012). Split loyalties: football is a community business. Soccer \& Society, 13(3), 377-391.

Illouz, E. (2009). Emotions, imagination and consumption. Journal of Consumer Culture, 9(3), 377-413.

Kennedy, D. (2012). Football stadium relocation and the commodification of football: The case of Everton supporters and their adoption of the language of commerce. Soccer \& Society, 13(3), 341-358.

Kennedy, P., \& Kennedy, D. (2012). Football supporters and the commercialisation of football: comparative responses across Europe. Soccer \& Society, 13(3), 327-340.

Kiousis, S. (2002). Interactivity. A concept explication. New Media \& Society, 4(3), 355-383.

Mahony, D. F., Madrigal, R., \& Howard, D. R. (1999). The effect of individual levels of selfmonitoring on loyalty to professional football teams. International Journal of Sports Marketing and Sponsorship, 1, 146-167.

McDonald, H., Leckie, C., Karg, A., \& Zubcevic-Basic, N. (2017). Female season ticket holders: how their satisfaction is derived differently from males. European Sport Management Quarterly.

Millward, P. (2013). New football directors in the twenty-first century: profit and revenue in the English Premier League's transnational age. Leisure Studies, 32(4), 399-414.

Nash, R. (2000). Globalised football fandom: Scandinavian Liverpool FC supporters. Football Studies, 3(2), 5-23.

Numerato, D. (2015). Who Says 'No to Modern Football?' Italian Supporters, Reflexivity, and Neo- Liberalism. Journal of Sport and Social Issues, 39(2), 120-138.

Oppenhuisen, J., \& van Zoonen, L. (2006). Supporters or customers? Fandom, marketing and the political economy of Dutch football. Soccer \& Society, 7(1), 62-75.

Ritzer, G., \& Jurgenson, N. (2010). Production, Consumption, Prosumption The nature of capitalism in the age of the digital 'prosumer'. Journal of Consumer Culture, 10(1), 13-36.

Rojek, C. (2001). Celebrity. London \& Chicago: Reaktion. 
Santomier, J. (2008). New media, branding and global sports sponsorship. International Journal of Sports Marketing \& Sponsorship, 10(1), 15-28.

Tapp, A., \& Clowes, J. (2002). From 'carefree casuals' to 'professional wanderers'.

Segmentation possibilities for football supporters. European Journal of Marketing, 36(11/12), $1248-1269$.

Taylor, I. (1971). Soccer consciousness and soccer hooliganism. In S. Cohen (Ed.), Images of Deviance (Penguin, pp. 134-164). Harmmondsworth.

UEFA. (2015). National association guide to marketing. UEFA.

Walsh, A. J., \& Giulianotti, R. (2001). This sporting mammon! A normative critique of the commodification of sport. Journal of the Philosophy of Sport, VVVIII, 53-77.

Williams, J. (2006). 'Protect Me From What I Want': Football Fandom, Celebrity Cultures and 'New' Football in England. Soccer \& Society, 7(1), 96-114. 


\section{Appendix}

Table 1: Profile of the selected countries

\begin{tabular}{|l|l|l|l|l|l|l|l|}
\hline Country & Region & $\begin{array}{l}\text { Pop. } \\
(000) \\
(2014)\end{array}$ & $\begin{array}{l}\text { GDP per } \\
\text { capita } \\
\text { (US\$) } \\
(2014)\end{array}$ & $\begin{array}{l}\text { Human } \\
\text { Dev. Index } \\
(2013) 3\end{array}$ & $\begin{array}{l}\text { Most } \\
\text { popular } \\
\text { sports }\end{array}$ & $\begin{array}{l}\text { UEFA } \\
\text { rankings for } \\
\text { club comp.4 }\end{array}$ & $\begin{array}{l}\text { No. of teams in the } \\
\text { top tiers of the } \\
\text { league structure }\end{array}$ \\
\hline Armenia & $\begin{array}{l}\text { Eastern } \\
\text { Europe }\end{array}$ & 30261 & 3622.21 & 0,733 & $\begin{array}{l}\text { Football } \\
\text { Chess } \\
\text { Wrestling }\end{array}$ & 49 & $\begin{array}{l}14 \text { (2016) } \\
6 \text { - Premier League5 } \\
8 \text { - First League }\end{array}$ \\
\hline England & $\begin{array}{l}\text { Western } \\
\text { Europe }\end{array}$ & $\begin{array}{l}44 \\
2461\end{array}$ & 40620.022 & 0,9072 & $\begin{array}{l}\text { Football } \\
\text { Cricket } \\
\text { Rugby }\end{array}$ & 2 & $\begin{array}{l}92 \text { (2016/17) } \\
20 \text { - Premier League } \\
24 \text { - Championship } \\
24 \text { - League 1 } \\
24 \text { - League 2 }\end{array}$ \\
\hline
\end{tabular}

